This document is the accepted manuscript version of the following article:

Künzle, R., Pronk, W., Morgenroth, E., \& Larsen, T. A. (2015). An energy-efficient membrane bioreactor for on-site treatment and recovery of wastewater. Journal of water Sanitation and Hygiene for Development, 5(3), 448-455.

https://doi .org/10.2166/washdev.2015.116

\title{
An energy-efficient membrane bioreactor for on-site treatment and recovery of wastewater
}

Rahel Künzle ${ }^{\mathrm{a}}$, Wouter Pronk ${ }^{\mathrm{a}}$, Eberhard Morgenroth ${ }^{\mathrm{a}, \mathrm{b}}$ and Tove A. Larsen ${ }^{\mathrm{a},{ }^{*}}$

\author{
a Eawag, Swiss Federal Institute of Aquatic Science and Technology, 8600 Dübendorf, Switzerland \\ ${ }^{b}$ ETH Zurich, Institute of Environmental Engineering, 8093 Zurich, Switzerland \\ * corresponding author: tove.larsen@eawag.ch
}

\section{ABSTRACT}

The present study describes the development of a new type of aerated membrane bioreactor dubbed BAMBi for on-site treatment of high-strength wastewater (a mixture of grey and beige water). The treated wastewater is reused for flushing and personal hygiene. BAMBi is an adaptation of a gravity-driven membrane (GDM) reactor, originally developed for the purpose of treating river water to drinking water quality. Initially, a series of reactor configurations were tested and it was found that the simplest possible configuration could treat the wastewater to an acceptable standard, provided that a polishing step for color removal and disinfection was introduced. Chlorine addition and chlorine production by electrolysis were tested as possible polishing steps. Both methods were suitable. The energy consumption of BAMBi is very low for an on-site application.

\section{KEYWORDS}

urban slums, maintenance, sustainable development, Blue Diversion, resilience 


\section{ABBREVIATIONS}

BAMBi Biologically activated membrane bio reactor

COD Chemical oxygen demand

GDM Gravity driven membrane

MBBR Moving bed biofilm reactor

MBR Membrane bio reactor

SCR Screen

SED Sedimentation

TF Trickling filter

TMP Trans membrane pressure

TSS Total suspended solids

UDDT Urine diverting dry toilet

UF Ultra filtration

WHO World Health Organization

\section{INTRODUCTION}

Worldwide, 2.5 billion people have no access to a safe toilet (UNICEF \& WHO 2012).

Especially for the population in urban slums, it is difficult to make available suitable technology that provides personal and urban hygiene as well as adequate water pollution control. According to UN Habitat (2013), presently more than 2.6 billion people live in slums and sanitation belongs to the least developed parts of urban infrastructure in all developing regions.

Sewer-based urban water management is no option for urban slums, which are in many cases informal settlements without any provision of urban infrastructure. Therefore the Blue Diversion toilet (Larsen et al. subm.) was developed as an adaptation of the urine-diverting dry toilet (UDDT), which in many cases is not well accepted by users. The main adaptation is the availability of water for hand washing as well as for anal and menstrual hygiene without reliance on piped-in water and without any production of wastewater. 
This paper describes the development of a reactor, which can treat a mixture of grey water (hand wash water) and beige water (wastewater resulting from anal cleansing; for definitions of "color coding" of wastewater sources see, e.g., Tilley, 2013). The main part of the excretions will be collected separately below the toilet and treated in a semi-centralized Resource Recovery Plant (Larsen et al. subm.). The resulting wastewater to be treated is thus a mixture of grey and beige water, which can be designated as grey-beige water.

Setting up on-site treatment in an urban slum places high demands on resilience, lowmaintenance, and costs. It was hypothesized that for the rather simple process of treating grey-beige water, it would be possible to set up a resilient and economically viable technology based on the Gravity Driven Membrane (GDM) reactor. This reactor type has been developed for on-site treatment of surface water to drinking water quality for use in developing countries (Peter-Varbanets et al. 2010). In the GDM reactor, surface water is filtered through an Ultra Filtration (UF) membrane using gravity as the only driving force to support a continuous flux of water. Due to biological activity in the biofilm on the membrane surface, which includes grazing by higher organisms (Derlon et al. 2012), the flux rapidly stabilizes without any cleaning measures, albeit on a relatively low level. For on-site settings in developing countries, it is essential to avoid regular maintenance such as cleaning, and with decreasing costs of UF membranes, the technology has become affordable for producing small amounts of drinking water for family use, even at low flow rates (Peter-Varbanets et al. 2010).

With GDM technology, a stable flux of around $4-10 \mathrm{~L} \cdot \mathrm{m}^{-2} \cdot \mathrm{h}^{-1}$ is obtained with surface water containing up to around $50 \mathrm{~g}_{\mathrm{COD}} \mathrm{m}^{-3}$ (Peter-Varbanets et al. 2010). At higher organic loads without aeration, oxygen restricted conditions may occur, which lead to more dense fouling layers and lower flux values (Peter-Varbanets et al. 2012). The Blue Diversion toilet was designed for 10 persons each using the toilet 5 times a day with a water consumption of $1.5 \mathrm{~L}$ per toilet visit (Larsen et al. subm.). Assuming a feces production of $90 \mathrm{~g} \operatorname{coD} \cdot \mathrm{p}^{-1} \cdot \mathrm{d}^{-1}$ and $5 \%$ 
loss of feces to the flush $\&$ wash water ${ }^{1}$, this results in a concentration of $600 \mathrm{gcoD}^{\cdot} \mathrm{m}^{-3}$, even without counting soap, blood and urine and thus much higher than the surface water treated in the GDM units discussed above. Therefore, the system set-up was adapted as shown in Figure 1 , with the aim of reducing the organic loading in one or more simple pre-treatment units, followed by a GDM-based unit (either with or without aeration) for removal of COD and pathogens. Conceptually one can distinguish between (a) GDM based reactors (no aeration and no mixing), (b) GDM based reactors with low aeration (aeration only for oxygen transfer and not for high shear at the membrane surface), and (c) membrane bioreactors with high aeration (aeration for both oxygen transfer and high shear). The GDM based reactor with low aeration is referred to as BAMBi (Biologically Activated Membrane Bio Reactor).

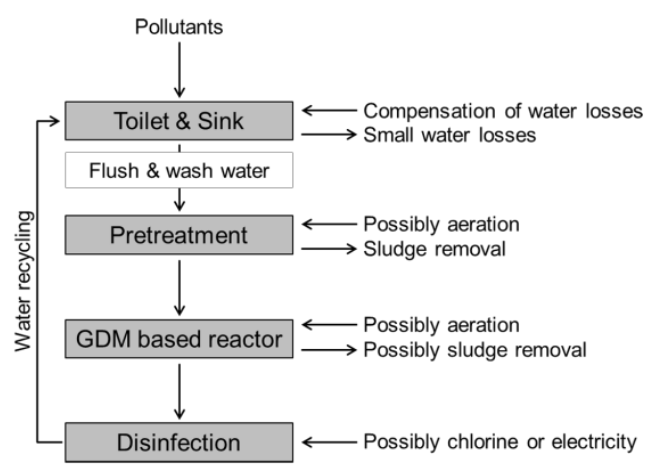

Figure 1: Water treatment using pretreatment followed by GDM based reactor combined with a disinfection step and reusing water for washing and flushing (Note: Feces and urine are diverted from this water cycle).

The six treatment configurations tested are described in the section Methods and listed in Table 1. Based on these six tests (in two sequential trials), the best reactor configuration was established. In a long-term test it was evaluated whether the chosen reactor configuration would lead to stable flux through the membrane without any maintenance being applied.

\footnotetext{
${ }^{1}$ The assumption that $5 \%$ of the feces would be lost to the flush \& wash water was made at the beginning of the design process. With increasing knowledge of the design features, the assumption was lowered to $2.5 \%$, however still giving rise to high-strength wastewater.
} 


\section{METHODS}

\section{Feed water}

Simulated grey-beige water consisted of a mixture of feces and urine. In phase C, a local soap from Kampala and/or calf blood was added. The estimated composition is shown in SI-Table 1.

\section{System set up}

UF membranes. Flatsheet polyethersulfone membranes (Microdyn Nadir, Germany) with a nominal cutoff of $100 \mathrm{kDa}$ were used. The clean water permeability of the membrane was 346 $\pm 20 \mathrm{~L} \mathrm{~h}^{-1} \mathrm{~m}^{-2}$ bar $^{-1}$ (viscosity corrected to $20^{\circ} \mathrm{C}$ ). For further details of the set-up, see SI.

Experimental set up of Phases A, B and C. The experiments were set up according to Figure 1 and Table 1 with Phase B starting on day 116 and Phase C on day 165. Soap and blood were only added in phase $\mathrm{C}(\mathrm{C} 1)$; recycling and the disinfection were introduced in $\mathrm{C} 2$ and $\mathrm{C} 3$. The following pretreatment options were tested alone or in combination: sedimentation (SED), filtration through a screen (SCR; pore size 500 and $100 \mu \mathrm{m}$ ), trickling filter using plastic cross corrugated structured packing as biofilm support media (TF), and an aerated Moving Bed Biofilm Reactor (MBBR; filled with well-used Kaldnes media (Type K1) and started up 6 days before the beginning of the experiment). The main treatment unit was an aerated (4-6 $L_{\text {air }}$ per $L_{\text {reactor volume }}$ and hour) or non-aerated reactor based on the GDM principle.

Sludge was not purposefully removed from the units during the experimental period, but $500 \mathrm{~mL}$ mixed reactor content/week was removed for analysis.

Table 1: Three parallel reactors (Units $1-3)$ where tested in three experimental phases (A C) in different combinations of a GDM based reactor with pretreatment (SED = Sedimentation 
in settling tank, SCR $=$ Screen, TF $=$ Trickling filter, MBBR $=$ Moving Bed Biofilm Reactor, None $=$ No pretreatment).

\begin{tabular}{|c|c|c|c|c|c|c|c|c|c|}
\hline \multirow[t]{2}{*}{ Exp. Phase } & \multicolumn{5}{|c|}{ Pretreatment } & \multicolumn{3}{|c|}{ Main Reactor based on GDM } & \multirow{2}{*}{$\begin{array}{l}\text { Feces / Urine } \\
\text { (\% of excretion*) }\end{array}$} \\
\hline & SED & SCR & TF & MBBR & None & & eration & Aeration & \\
\hline $\mathrm{A} 1$ & $X$ & & & & & Unit 1 & & $x$ & $5 / 2$ \\
\hline $\mathrm{A} 2$ & $x$ & $x$ & & & & Unit 2 & $x$ & & $5 / 2$ \\
\hline $\mathrm{A} 3$ & $x$ & & $\mathrm{X}$ & & & Unit 3 & $x$ & & $5 / 2$ \\
\hline B1 & & & & $x$ & & Unit 1 & & $x$ & $2.5 / 1$ \\
\hline $\mathrm{B} 2$ & & & & & $x$ & Unit 2 & $x$ & & $2.5 / 1$ \\
\hline B3 & & & & & $x$ & Unit 3 & & $x$ & $2.5 / 1$ \\
\hline $\mathrm{C} 1$ & & & & & $x$ & Unit 1 & & $x$ & $2.5 / 1$ \\
\hline $\mathrm{C} 2$ & & & & & $x$ & Unit 2 & & $x$ & $2.5 / 1$ \\
\hline C3 & & & & & $x$ & Unit 3 & & $x$ & $2.5 / 1$ \\
\hline
\end{tabular}

* Assuming a feces production of $90 \mathrm{gCOD} \mathrm{p}^{-1} \mathrm{~d}^{-1}$ and a urine production of $1 \mathrm{~L} \mathrm{p}^{-1} \mathrm{~d}^{-1}$. Membrane installation: $0.3 \mathrm{~m}^{2} \mathrm{p}^{-1}$.

\section{Polishing step}

The results showed that the effluent from the biological treatment would need a post treatment in order to remove color and prevent regrowth of pathogens (see Results section). Chlorine addition as well as chlorine production by electrolysis was tested (details see $\mathrm{SI}$ ).

\section{Analytical Methods}

All details on analytical methods are presented in SI.

\section{RESULTS}

\section{Establishing the optimal system configuration}

During Phase A and B different pretreatment technologies and operation modes (Table 1) were evaluated with respect to resulting flux (at a transmembrane pressure (TMP) of $31 \mathrm{mbar}$ corresponding to approximately $31 \mathrm{~cm}$ water column) and removal of total COD ( $\left.\mathrm{COD}_{\text {tot }}\right)$.

The results from Phase A (A1-A3; Figure 2) show that sedimentation was quite effective for $\mathrm{COD}_{\text {tot }}$ removal $(55 \%, \mathrm{~A} 1)$, but the resulting concentration of the sludge was low (results not shown). Furthermore, a screen or a trickling filter between the sedimentation and the GDM- 
based reactor (A2 and $A 3)$ did neither result in a decrease of the final effluent COD concentration nor in a flux increase.

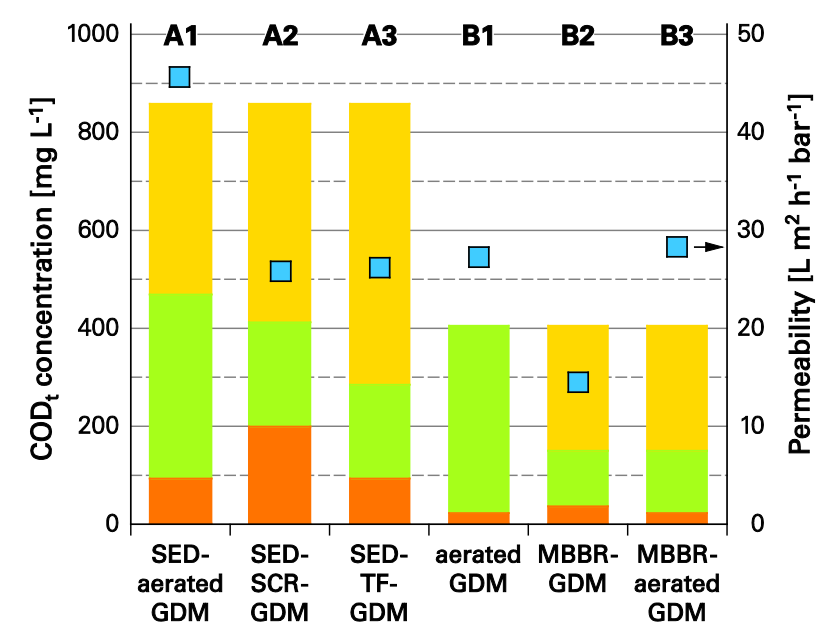

Figure 2: Comparison of different operation modes in Phase A and B (cf. Table 1): (A) high inlet concentration of $\mathrm{COD}_{\text {tot }}\left(5 \%\right.$ of feces) and sedimentation; $(B)$ low inlet concentration of $\mathrm{COD}_{\text {tot }}$ ( $2.5 \%$ of feces) and no sedimentation. Bars are divided into 3 sections indicating removal of $\mathrm{COD}_{\text {tot }}$ in pretreatment (upper part), removal in the GDM-based reactor (middle part) and concentration of COD in permeate (lower part). The permeability is shown as squares. SED: Sedimentation tank, SCR: Screen, TF: Trickling filter, MBBR: Moving Bed Biofilm Reactor and GDM: Gravity Driven Membrane filtration unit.

Parallel developments in toilet design showed that the loading of excreta was overestimated whereupon the inlet concentration in Phase B were halved. The results show that similar effluent COD concentrations were obtained in all systems tested in Phase $B$, independent of the pretreatment, although the effluent concentration from the non-aerated GDM-based unit was slightly higher (36 compared to 25 (B1) and $21 \mathrm{mg} \mathrm{L}^{-1}$ (B3)). The flux in the non-aerated GDMunit (B2) was significantly lower than in the aerated units (B1 and B3). Considering both the performance (COD and flux) and simplicity of design and operation, it was concluded that an aerated GDM-based unit without any pretreatment (as in B1) would be the optimal reactor configuration. In Phase $\mathrm{C}$, the long-term stability of this reactor type was tested (see next section). This aerated GDM-based reactor is a hybrid between an MBR and a GDM reactor, and was named BAMBi. 


\section{Long-term stability of BAMBi}

A final Phase $\mathrm{C}$ was performed in order to test the long-term stability and performance variation, including recycling of the permeate as is the case in the Blue Diversion Toilet. All three GDM units were run as single-stage BAMBi (fed directly without pretreatment and aerated). The detailed feeding protocols are reported in SI. The entire data set from all three phases was used to evaluate the stability.

Permeability. Next to the removal of COD, the permeability of the membrane is the most important characteristic of Bambi. The membrane from unit 2, which had been run anaerobically during the entire period of Phase A and B, was chemically cleaned on day 153 . Afterwards a clean water permeability of $310 \mathrm{~L} \mathrm{~m}^{-2} \mathrm{~h}^{-1}$ bar $^{-1}$ was achieved as compared to an initial clean water permeability of $370 \pm 8 \mathrm{~L} \mathrm{~m}^{-2} \mathrm{~h}^{-1} \mathrm{bar}^{-1}$. The fouling occurring during anaerobic periods is thus to a large degree reversible.

The permeability in Phase $\mathrm{C}$ was in general higher than in Phase $\mathrm{A}$ and $\mathrm{B}$, but the variation was much larger. An average permeability of $84 \pm 30 \mathrm{~L} \mathrm{~m}^{-2} \mathrm{~h}^{-1}$ bar $^{-1}$ was found (excluding the data during the time of adjustment after chemical cleaning (GDM 2 from day 150 to 170)).

The higher permeability during Phase $\mathrm{C}$ is observed in all three reactors despite the higher organic loading of unit 1 (due to the addition of blood and/or soap) and the recycling of the permeate in unit 2 and 3 . The higher permeability during Phase $C$ could be due to the higher temperature, which may support more grazing on the biofilm. 


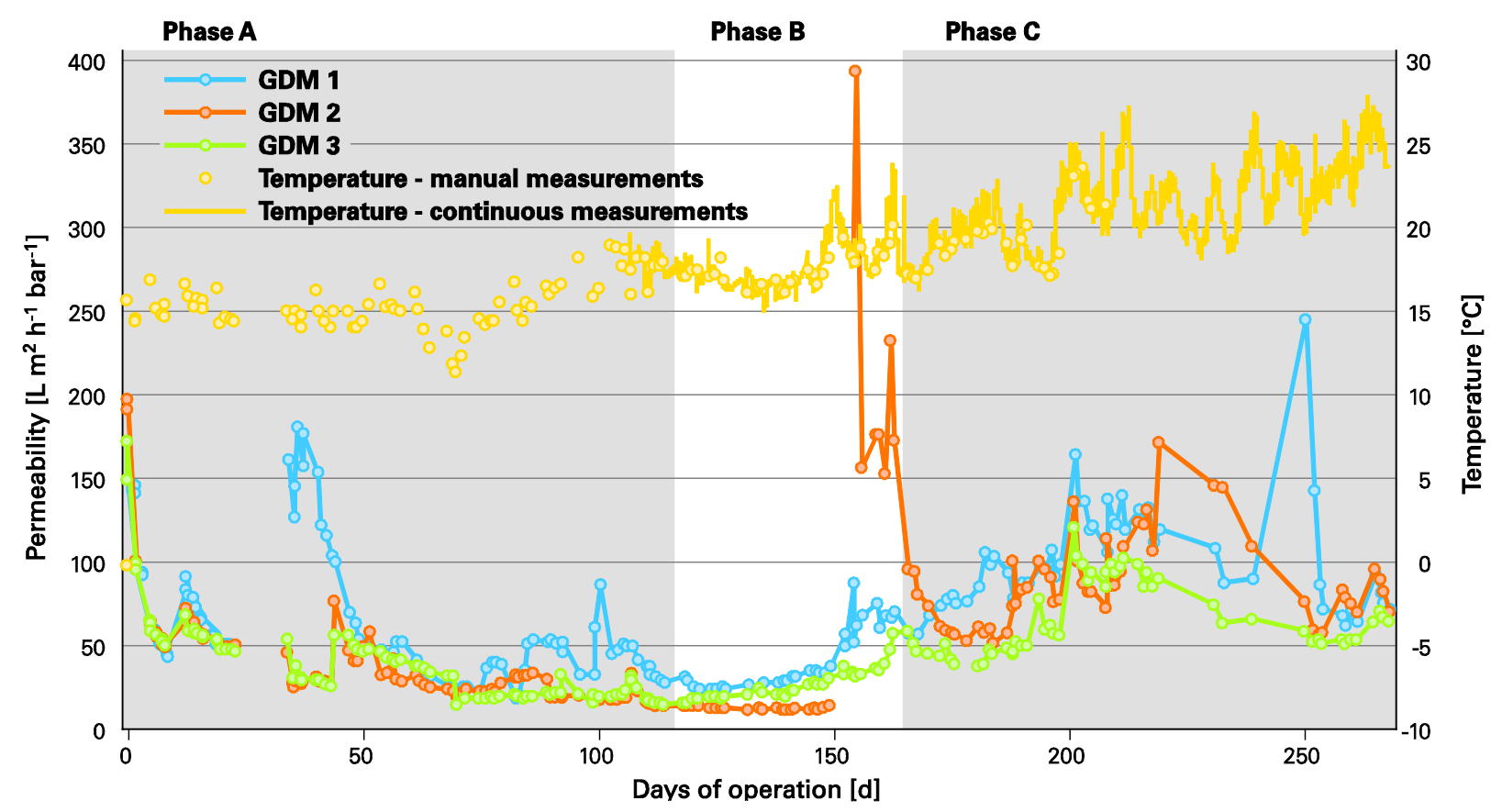

Figure 3: Permeability of the three GDM-based units and the water temperature over time. The three Phases (A, B, C) are indicated on top. In Phase C, $C 1$ is additionally fed with blood and/or soap, whereas C2 and C3 are run with $80 \%$ recycling of permeate (but without soap/blood).

Influence of feed composition on permeability and COD reduction. On day 165 , soap addition in $\mathrm{C} 1$ was started, resulting in an increase of the inlet $\mathrm{COD}_{\text {tot }}$ by a factor 2.4 . An increased permeability is observed, but this may be due to an increase in temperature (Table 2 and Figure 3). The permeate COD concentration and color did not change significantly following soap addition. From day 209 , blood and soap were added in $\mathrm{C} 1$. The inlet $\mathrm{COD}_{\text {tot }}$ concentration was about $75 \%$ higher compared to the soap only experiment, but the permeate color and the $\mathrm{COD}_{\text {tot }}$ reduction did not change significantly (Table 2). Instead the permeability increased further (Table 3).

As an effect of $80 \%$ recycling ( $\mathrm{C} 2$ and $\mathrm{C} 3$ ), the inlet $\mathrm{COD}_{\text {tot }}$ concentration got much higher because the entire load of COD was contained in $20 \%$ of the inlet (see Table 2 ). The permeate $\mathrm{COD}_{\text {tot }}$ concentration increased by a factor of 2 within 80 days and the color of the effluent got more intense. No impact on permeability was observed (Table 2). 
Table 2: Average $\mathrm{COD}_{\text {tot }}$ concentrations [mg COD L-1], resulting $\mathrm{COD}_{\text {tot }}$ reduction and permeability $\left[\mathrm{L} \cdot \mathrm{m}^{-2} \cdot \mathrm{h}^{-1} \cdot \mathrm{bar}^{-1}\right]$ during Phase $\mathrm{C}$ and the results from Phase $\mathrm{B}$ as a comparison

\begin{tabular}{|c|c|c|c|c|c|c|c|c|}
\hline \multirow[b]{3}{*}{ Inlet [mgCOD L-1] } & \multirow{2}{*}{\multicolumn{2}{|c|}{$\begin{array}{c}\text { B } \\
\text { No additives } \\
\text { No recycling }\end{array}$}} & \multirow{2}{*}{\multicolumn{2}{|c|}{$\begin{array}{c}\text { C1 } \\
+ \text { Soap }\end{array}$}} & \multicolumn{2}{|c|}{ C1 } & \multicolumn{2}{|c|}{$\mathrm{C} 2$ and $\mathrm{C3}$} \\
\hline & & & & & + Soa & Blood & $\begin{array}{l}\text { No } \\
80 \%\end{array}$ & $\begin{array}{l}\text { ves } \\
\text { ling }\end{array}$ \\
\hline & 374 & \pm 76 & 898 & \pm 218 & 1567 & \pm 367 & 1546 & \pm 338 \\
\hline Effluent [mgCOD L-1] & 35 & \pm 8 & 35 & \pm 8 & 50 & \pm 17 & 66 & \pm 21 \\
\hline COD Reduction & $89 \%$ & $\pm 5 \%$ & $96 \%$ & $\pm 0 \%$ & $96 \%$ & $\pm 0 \%$ & $95 \%$ & $\pm 1 \%$ \\
\hline Permeability [ $\left.\mathrm{L} \mathrm{m}^{-2} \mathrm{~h}^{-1} \mathrm{bar}^{-1}\right]$ & 42 & \pm 19 & 90 & \pm 31 & 120 & \pm 10 & 74 & \pm 25 \\
\hline
\end{tabular}

* With $80 \%$ recycling of the effluent, the concentration in the inlet rise by a factor of 5 in order to keep the load constant.

Small deviations in load are inevitable.

Independent of loading and recycling conditions, COD removal was $\geq 95 \%$ during Phase C. With an assumed load of $3-12 \mathrm{~g}_{\mathrm{COD}} \mathrm{p}^{-1} \mathrm{~d}^{-1}$, this results in a net COD emission from BAMBi of less than $0.15-0.6 \mathrm{~g}_{\operatorname{coD}} \mathrm{p}^{-1} \mathrm{~d}^{-1}$. This organic load should preferably be degraded in the polishing step in order to prevent accumulation of organic matter and regrowth of microorganisms.

If the polishing step is based on chlorination as suggested in this paper, stable nitrification will be important in order to economize on chlorine. Although in many cases, full nitrification was observed, a stable nitrification was not obtained throughout the experimental period (data not shown). This is one of the most important topics for further research on BAMBi.

\section{Total suspended solids (TSS)}

A large degree of sludge stabilization was found in the reactors (see SI Figure 4). A low sludge production reduces the need for sludge removal, which can thus take place less frequently, but also leads to higher oxygen consumption for sludge stabilization. More research is needed in order to establish the most suitable sludge removal protocol.

\section{Polishing step}

Chlorine addition. The experiments showed that chlorine addition of $0.225 \mathrm{~g} \mathrm{p}^{-1} \mathrm{~d}^{-1}$ could remove color and sanitize the water with a suitable amount of residual chlorine eight hours after dosage $(0.8 \mathrm{mg} / \mathrm{L}$ as compared to a maximum of $5 \mathrm{mg} / \mathrm{l}$ acceptable even for drinking water). For details see SI. 
Electrolysis. The experimental results using a graphite anode showed that a constant voltage of $2.5 \mathrm{~V}$ was optimal for decreasing the color intensity (details see SI). Chlorine production was detected, but no data on residual chlorine are available. The graphite electrode, however, was not stable during operation, but dissolved rapidly. Further investigation in terms of electrode material, voltage and flow rate through the electrolysis cell have a large potential to improve the application of electrolysis for de-colorization and sanitizing purposes.

\section{DISCUSSION}

Based on the results from the experimental Phases $A$ and $B$, it was concluded that a single aerated GDM-based reactor (i.e. BAMBi) is well suited to treat the grey-beige water generated in the Blue Diversion toilet. No pretreatment steps could be justified.

BAMBi is compared to its two 'parent' reactors, the MBR and the GDM in Table 3. From this it is clear that the main advantage of BAMBi is that wastewater can be treated in a membrane reactor without any regular maintenance for membrane cleaning. The main disadvantage is the relatively low flux through the membrane. BAMBi will thus primarily be competitive in decentralized settings with low water consumption.

Table 3: Comparison of BAMBi with the parent reactor types MBR and GDM. The data from Bambi is based on lab experience and tested ranges.

\begin{tabular}{|c|c|c|c|c|c|c|c|}
\hline $\begin{array}{l}\text { Reactor } \\
\text { type }\end{array}$ & Typical medium & 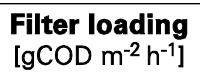 & Active aeration & $\begin{array}{l}\text { Membrane } \\
\text { cleaning }\end{array}$ & $\begin{array}{l}\text { Pressure } \\
\text { [mbar] }\end{array}$ & $\underset{\left[\mathrm{L} \mathrm{m}^{-2} \mathrm{~h}^{-1}\right]}{\text { Flux }}$ & $\begin{array}{c}\text { Energy demand } \\
{\left[\mathrm{kWh} \mathrm{m} \mathrm{m}^{-3}\right]}\end{array}$ \\
\hline MBR & Wastewater & $0.02-5.0$ & Yes & Yes & $300-500$ & $20-100$ & $0.4-2.5^{2}$ \\
\hline GDM & Surface water & $0.01-0.02^{1}$ & No & No & $40-150^{1}$ & $4-10^{1}$ & $\sim 0$ \\
\hline BAMBi & Wastewater & $0.1-1.8$ & Yes & No & $20-100$ & $0.5-1.5$ & $0.5-1^{3}$ \\
\hline
\end{tabular}

1 Peter-Varbanets et al. (2010); ${ }^{2}$ Krzeminski et al. (2012); ${ }^{3}$ own results, not discussed here.

Comparing the operation of GDM based reactors with and without aeration (Figure 2 and 3) clearly demonstrates that oxygen is required for a good functioning of the GDM process, which 
corresponds to previous investigations with drinking water treatment (Peter-Varbanets et al. 2011). Although this was expected, it has to our knowledge never been explicitly shown.

Phase $\mathrm{C}$ showed that a stable, albeit variable flux can be maintained in the gravity-driven BAMBi. Obviously, the success of the reactor in a real-life setting will depend on many external factors (energy availability, usage patterns, etc.), but such aspects must be optimized in more practical experiments, including field studies.

Our short experiments with chlorination and electrolysis showed that both technologies are in principle suitable for color removal and for sanitizing purposes. Optimizing these two processes, however, goes beyond the scope of the present study.

\section{CONCLUSIONS}

An energy-efficient, self-maintaining on-site water recovery reactor for the treatment of greybeige water was developed. Aerated and non-aerated reactors based on the gravity driven membrane (GDM) units with different combinations of pretreatments were tested. The following conclusions are made:

- Simple aeration of a GDM-based reactor without any pre-treatment was effective and for an on-site application generally superior to a GDM-based reactor in combination with pretreatment. The resulting reactor was named $\mathrm{BAMBi}$.

- Degradation of organic matter in BAMBi was above $95 \%$.

- Membrane permeability in BAMBi was stable over months, albeit variable. At temperatures between 20 and $25^{\circ} \mathrm{C}$, permeability varied between 50 and $150 \mathrm{~L} \mathrm{~m}^{-2} \mathrm{~h}^{-1}$ bar $^{-1}$. At lower temperatures, a lower permeability was observed, but no systematic tests for temperature dependency were conducted.

- Water treated in $\mathrm{BAMBi}$ is slightly colored and not stable from a microbiological point of view. Electrolysis as well as chlorine addition were effective for color removal and for 
maintaining a concentration of excess chlorine ensuring hygiene. Stable nitrification was not obtained; this would be important for a polishing step based on chlorine

- The development of BAMBi shows that resilience of complex biological systems can be obtained in low-loaded systems, even for very small on-site applications.

\section{ACKNOWLEDGEMENTS}

The project was funded by the Bill and Melinda Gates Foundation, for which grateful acknowledgment is made. The technical as well as the laboratory staff of the process engineering department of Eawag are thanked for the invaluable help in setting up the experiments and analyzing samples.

\section{REFERENCES}

Dasharathy, S. S., Mumford, S. L., Pollack, A. Z., Perkins, N. J., Mattison, D. R., Wactawski-Wende, J. \& Schisterman, E. F. 2012 Menstrual Bleeding Patterns Among Regularly Menstruating Women. Am. J. Epidemiol. 175(6), 536-545.

Derlon, N., Peter-Varbanets, M., Scheidegger, A., Pronk, W. \& Morgenroth, E. 2012 Predation influences the structure of biofilm developed on ultrafiltration membranes. Water Res. 46(10), 33233333.

Krzeminski, P., van der Graaf, J. H. \& van Lier, J. B. 2012 Specific energy consumption of membrane bioreactor (MBR) for sewage treatment. Water Sci. Technol. 65(2), 380-392.

Larsen, T.A., Gebauer, H., Gründl, H., Künzle, R., Lüthi, C., Messmer, U., Morgenroth, E. \& Ranner, B. (subm.) Blue Diversion: A Resource-Oriented Sanitation Solution for Informal Settlements. Submitted to J. Water, Sanitation Hyg. Dev.

Peter-Varbanets, M., Hammes, F., Vital, M. \& Pronk, W. 2010 Stabilization of flux during dead-end ultralow pressure ultrafiltration. Water Res. 44(12), 3607-3616. 
Peter-Varbanets, M., Margot, J., Traber, J. \& Pronk, W. 2011 Mechanisms of membrane fouling during ultra-low pressure ultrafiltration. J. Membr. Sci. 377 (1-2), 42-53.

Peter-Varbanets, M., Gujer W. \& Pronk, W. 2012. Intermittent operation of ultra-low pressure ultrafiltration for decentralized drinking water treatment. Water Res., 46, 3272-3282.

Schouw, N. L., Danteravanich, S., Mosbaek, H. \& Tjell, J.C. 2002 Composition of human excreta -a case study from Southern Thailand. Sci. Total Environ. 286, 155-166.

Tilley, E. (2013) Conceptualizing sanitation systems to account for new complexities in processing and management. In: Source Separation and Decentralization for Wastewater Management (Larsen, T.A., Lienert, J. \& Udert, K.M., eds.). IWA publishing, London, UK, pp. 227-240.

UNICEF \& World Health Organization 2012 Progress on Drinking Water and Sanitation: 2012 Update. UNICEF \& WHO, New York, 2012

UN Habitat (2013) State of the World's Cities 2012/2013: Prosperity of Cities. First published 2013 by Routledge for and on behalf of the United Nations Human Settlements Programme (UN-Habitat). http://sustainabledevelopment.un.org/content/documents/745habitat.pdf

World Health Organization 2006 Guidelines for safe recreational water environments. Geneva, World Health Organization. 